\title{
Development of a Control Algorithm for a Static VAR Compensator Used in Industrial Networks
}

\author{
Ljubiša Spasojević ${ }^{\dagger}$, Igor Papič ${ }^{*}$, and Boštjan Blažič ${ }^{*}$ \\ ${ }^{\dagger *}$ Faculty of Electrical Engineering, University of Ljubljana, Ljubljana, Slovenia
}

\begin{abstract}
In this paper a method for the development of a static VAR compensator (SVC) control algorithm is presented. The proposed algorithm has been designed with the objective of eliminating the negative impact of electric arc furnaces on the power system. First, a mathematical model of the proposed SVC controller in the d-q synchronous rotating coordinate system is developed. An analysis under dynamic and steady state conditions is also carried out. The efficiency of the presented controller is demonstrated by means of computer simulations of an actual steel-factory network model. The major advantages of the proposed controller are better flicker compensation, increased ability to regulate voltage and the need for only one-point network measurements.
\end{abstract}

Key words: Control algorithm, Electric arc furnaces, Flicker, SVC, TCR, Voltage fluctuation

\section{INTRODUCTION}

In the past decades the use of electric arc furnaces (EAFs) has grown rapidly mainly due to an increase in the use of steel. The time-varying nature of consumption and the non-linear voltage-current characteristic have a large negative influence on power quality. They are major sources of voltage oscillations in power systems, which can produce the effect known as flicker [1], [2]. In addition, EAFs consume a significant quantity of reactive power which may give rise to voltage instability in power systems without proper compensation. The lead role in reducing the negative impact of EAFs on power systems is performed by flexible AC transmission systems (FACTS) devices [3], [4].

Static VAR compensators (SVCs), based on conventional thyristor technology, can generate or consume reactive power. SVCs represent the most common and most widely used type of FACTS devices that are used also to compensate the negative impact of EAFs [5], [6]. In order to achieve a fast dynamic response with an SVC, which is limited by delays in reactive power measurement and thyristors ignition, an appropriate control algorithm has to be developed. The control algorithm of an SVC is an important part of its

Manuscript received Jun. 24, 2013; accepted Mar. 25, 2014

Recommended for publication by Associate Editor Kyeon Hur.

Corresponding Author: ljubisa.spasojevic@fe.uni-lj.si

Tel: +386 1476 8858, University of Ljubljana

*Faculty of Electrical Engineering, University of Ljubljana, Slovenia operation, because the dynamic characteristic of an SVC mostly depends on it [7].

Many different types of control algorithms have been researched and applied to SVCs. In [4] the control algorithm is based on a robust control strategy, in [8] stochastic models are used to predict the arc furnace reactive power and to enhance the compensator performance, [9] proposes a self-tuning PID controller, while in [10] a conventional PID controller has been proposed. Authors have also suggested SVC control schemes based on fuzzy logic [3], [11] and [12].

The main shortcomings of the control algorithms presented in the literature are their complexity in terms of a multiple measurement points requirement as in [3], or in terms of a complex load models requirement as in [7] and [8]. In addition, proper adjustment of the controller parameters, in order to achieve maximum utilization of the device, can be a difficult task and the parameters are often determined by a "trial and error" method [12]. This can be a time consuming process and it does not guarantee the achievement of the optimum operating point.

This paper deals with the mathematical derivation of a control algorithm in the feedback loop strategy for an industrial SVC. Combining P and PI controllers ensures good characteristics under both dynamic and steady-state conditions. The procedure for developing and testing the controller for an industrial SVC will be shown and its operation will be demonstrated by means of simulations of an actual industrial network. 


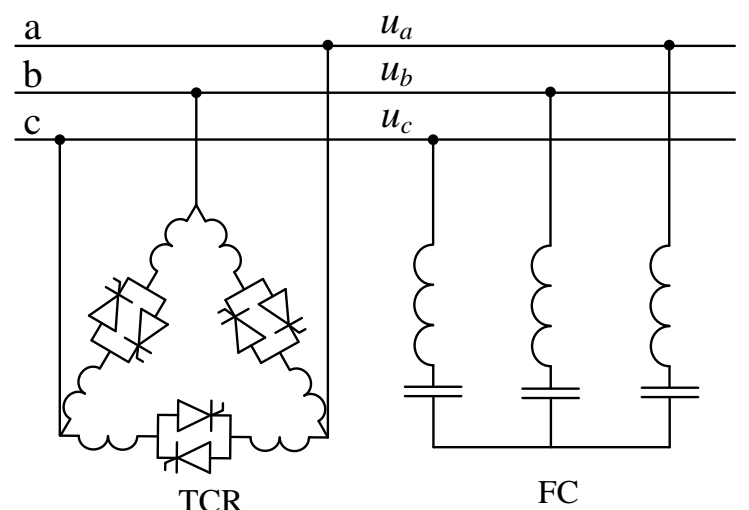

Fig. 1. Scheme of a TCR-FC.

The major advantages of the proposed controller are its good flicker compensation, its ability to regulate voltage and the need for measurements in only one network point. In addition, the control algorithm does not require an in-depth knowledge of the characteristics of the compensated load.

\section{STATIC VAR COMPENSATOR}

Fig. 1 shows the main circuit of a Thyristor-Controlled Reactor, Fixed Capacitor (TCR-FC) type of static VAR compensator.

This type of SVC can provide a generation of reactive power in both quadrants, capacitive and inductive. It is composed of parallel filter fixed capacitors (FCs) and a thyristor-controlled reactor (TCR). The fixed capacitors constantly supply the system with capacitive reactive power. They also filter the harmonics generated by the TCR and other loads in the system. The TCR provides variable inductive power. This type of SVC is used for reactive power compensation and voltage regulation. It can also be used for a reduction in the flicker level caused by EAF operation.

\section{COMPENSATION PRINCIPLE AND MATHEMATICAL MODEL OF A TCR}

It is widely recognized that rapid changes in the reactive power of electric arc furnaces cause voltage fluctuations at the point of connection. A TCR can quickly alter the inductive current in a continuous way according to system demands by changing the firing angle $(\alpha)$ of the thyristors connected in series with the reactor. By using a suitable controller for the firing angle $(\alpha)$ the consumption of reactive power from the power system, and in turn voltage fluctuations, can be decreased to an acceptable level. The control algorithm has an essential role in the proper and efficient operation of the TCR. For the design of the control algorithm the simplified equivalent scheme shown in Fig. 2 is used.

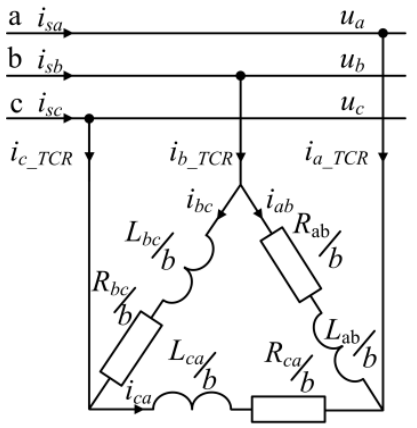

a)

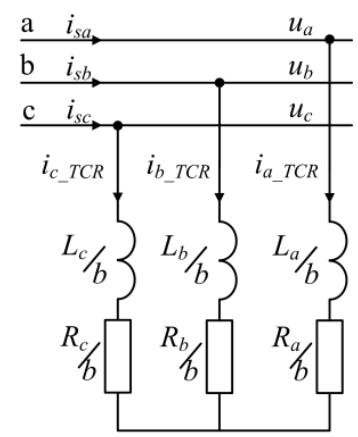

b)

Fig. 2 The simplified equivalent scheme of a TCR. (a) Delta configuration. (b) Star configuration.

In this figure $i_{s a}, i_{s b}$ and $i_{s c}$ are the system currents (currents from the power system), $u_{a}, u_{b}$ and $u_{c}$ are the phase-to-neutral voltages at the point of common coupling (PCC), $i_{a b}, i_{b c}$ and $i_{c a}$ are the currents through the reactors in the delta equivalent scheme, while $i_{a_{-} T C R}, i_{b_{-} T C R}$ and $i_{C_{-} T C R}$. are the currents through the reactors in the star equivalent scheme. In the star circuit, the currents through the reactors and the line currents of the TCR are the same. For simplicity, the star configuration will be used for the controller development, since the results are not dependent on the star or delta representation of the TCR circuit.

The proposed control algorithm is based on the continuous measurement of the system currents. When the SVC operates under dynamic conditions, the control algorithm calculates the angle of the thyristors ignition which changes the reactance of the TCR. This operation may be modelled by a variable factor $b$, as shown in Fig. 2. Factor $b$ is expressed in per-unit (p.u.) and can have a value between 0 and 1 . For a value equal to zero the current of the TCR is zero, while for value of one the current through the TCR is equal to one per-unit. Please note that factor $b$ is equal for the star and the delta TCR equivalent schemes (Fig. 2). The resistance in series with the reactor represents the losses of the TCR. For further derivation [according to Fig. 2(b)], the following per unit system is used:

$$
\begin{gathered}
i_{a}^{\prime}=\frac{i_{a_{-} T C R}}{i_{b}}, \quad i_{b}^{\prime}=\frac{i_{b_{-} T C R}}{i_{b}}, \quad i_{c}^{\prime}=\frac{i_{C_{-} T C R}}{i_{b}}, \\
u_{a}^{\prime}=\frac{u_{a}}{u_{b}}, \quad u_{b}^{\prime}=\frac{u_{b}}{u_{b}}, \quad u_{c}^{\prime}=\frac{u_{c}}{u_{b}}, \\
R_{a}^{\prime}=\frac{R_{a}}{Z_{b}}, \quad R_{b}^{\prime}=\frac{R_{b}}{Z_{b}}, \quad R_{c}^{\prime}=\frac{R_{c}}{Z_{b}}, \\
X_{a}^{\prime}=\frac{\omega_{b} L_{a}}{Z_{b}}, \quad X_{b}^{\prime}=\frac{\omega_{b} L_{b}}{Z_{b}}, \\
X_{c}^{\prime}=\frac{\omega_{b} L_{c}}{Z_{b}}, \quad Z_{b}=\frac{u_{b}}{i_{b}},
\end{gathered}
$$


where $i_{b}, u_{b}$ and $Z_{b}$ are the base values of the current, voltage and impedance, respectively, while $\omega_{b}$. is the synchronous angular speed of the fundamental network component. The following set of equations can be written based on the equivalent scheme shown in Fig. 2(b):

$$
\begin{aligned}
& u_{a}=\frac{L_{a}}{b} \frac{d i_{a_{-} T C R}}{d t}+i_{a} \frac{R_{a}}{b}, \\
& u_{b}=\frac{L_{b}}{b} \frac{d i_{b_{-} T C R}}{d t}+i_{b} \frac{R_{b}}{b}, \\
& u_{c}=\frac{L_{c}}{b} \frac{d i_{c_{-} T C R}}{d t}+i_{c} \frac{R_{c}}{b},
\end{aligned}
$$

or in p.u.:

$$
\begin{aligned}
& u_{a}^{\prime} b=\frac{X_{a}^{\prime}}{\omega_{b}} \frac{d i_{a}^{\prime}}{d t}+i_{a}^{\prime} R_{a}^{\prime}, \\
& u_{b}^{\prime} b=\frac{X_{b}^{\prime}}{\omega_{b}} \frac{d i_{b}^{\prime}}{d t}+i_{b}^{\prime} R_{b}^{\prime}, \\
& u_{c}^{\prime} b=\frac{X_{c}^{\prime}}{\omega_{b}} \frac{d i_{c}^{\prime}}{d t}+i_{c}^{\prime} \frac{R_{c}^{\prime}}{b} .
\end{aligned}
$$

By applying the dq transformation, a 3-phase system can be transformed into the $\mathrm{d}$-q synchronous rotation coordinate system (SRCS). Assuming that the phase inductances and phase resistances are equal ( $X$ and $R$, respectively), equation (6) can be written as (7) in the d-q SRCS when the Laplace transform is used:

$$
S\left[\begin{array}{c}
i_{d}^{\prime} \\
i_{q}^{\prime}
\end{array}\right]=\left[\begin{array}{cc}
-\frac{R^{\prime} \omega_{b}}{X^{\prime}} & \omega \\
-\omega & -\frac{R^{\prime} \omega_{b}}{X^{\prime}}
\end{array}\right]\left[\begin{array}{l}
i_{d}^{\prime} \\
i_{q}^{\prime}
\end{array}\right]+\frac{b \omega_{b}}{X^{\prime}}\left[\begin{array}{l}
u_{d}^{\prime} \\
u_{q}^{\prime}
\end{array}\right],
$$

where $s=d / d t$. In this case, both components $\left(i_{d}^{\prime}\right.$ and $\left.i_{q}^{\prime}\right)$ of the current that flows into the TCR are coupled by the angular speed $\omega$. The usual choice would be to set $\omega_{b}=\omega$.

Under steady state conditions, the values of $i_{d}^{\prime}$ and $i_{q}^{\prime}$ are constant, which is convenient for the derivation of the control algorithm. The currents can be expressed as:

$$
\begin{aligned}
& i_{d}^{\prime}\left[s+\frac{R^{\prime} \omega_{b}}{\mathrm{X}^{\prime}}\right]=\frac{b \omega_{b}}{\mathrm{X}^{\prime}} u_{d}^{\prime}+\omega i_{q}^{\prime} \\
& i_{q}^{\prime}\left[s+\frac{R^{\prime} \omega_{b}}{X^{\prime}}\right]=\frac{b \omega_{b}}{X^{\prime}} u_{q}^{\prime}-\omega i_{d}^{\prime} \\
& i_{d}^{\prime}=\frac{1}{s+\frac{R^{\prime} \omega_{b}}{\mathrm{X}^{\prime}}}\left[\frac{b \omega_{b}}{\mathrm{X}^{\prime}} u_{d}^{\prime}+\omega i_{q}^{\prime}\right]
\end{aligned}
$$

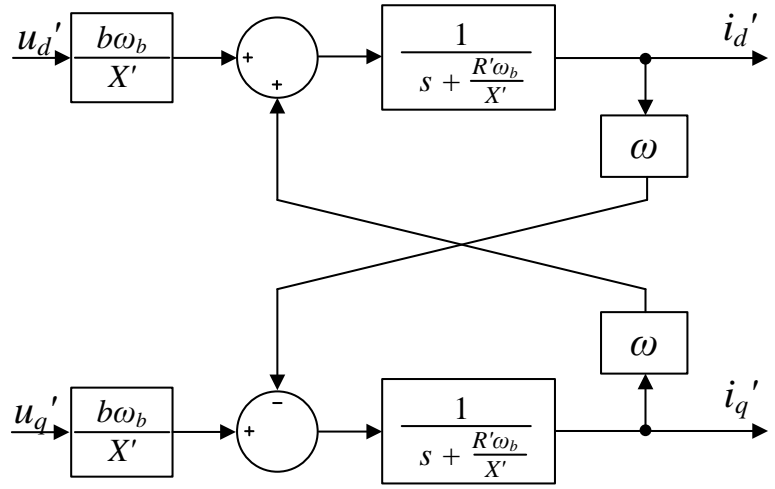

Fig. 3. Simplified mathematical model of a TCR.

$$
i_{q}^{\prime}=\frac{1}{s+\frac{R^{\prime} \omega_{b}}{X^{\prime}}}\left[\frac{b \omega_{b}}{X^{\prime}} u_{q}^{\prime}-\omega i_{d}^{\prime}\right]
$$

Based on equations (10) and (11), a simplified mathematical model of the TCR device in the d-q SRCS is obtained and shown in Fig. 3. The described model does not take into account the thyristors ignition delay which will be introduced in the next section.

\section{CONTROLler DESIGN}

The derivation of the control algorithm for the TCR device in the d-q SRCS starts from the simplified mathematical model shown in Fig. 3. Firstly, proper synchronization of the coordinate system must be made. With proper synchronization, the reactive component of the TCR current $\left(i_{q}^{\prime}\right)$ is proportional to the reactive power $(q)$ of the TCR device. The d-q SRCS is synchronized to the medium voltage (MV) level so that the angle $\varphi$ between the voltage vector of $u_{M V}$ (the voltage at the MV level) and d-axes of the d-q SRCS is equal to 0 .

From Fig. 3 it can be seen that a change in factor $b$ influences the value of $i_{q}^{\prime}$. Therefore, the desired value of $i_{q}^{\prime}$ can be generated by a suitable value of factor $b$. In fact, the susceptance of the TCR $\left(B_{T C R}\right)$ can be controlled by parameter $b$.

Now, the connection between the reactive component of the TCR current $\left(i_{q T C R}\right)$ and the reactive component of the system current $\left(i_{q s}\right)$ should be established. The system current $\left(i_{s}\right)$ flows from the power system to the EAF and its reactive component should be compensated to zero. Fig. 4 shows a simplified system configuration.

For point $\mathrm{A}$ it can be written as:

$$
i_{s}=i_{l}-i_{S V C}
$$

where $i_{s}, i_{S V C}$ and $i_{l}$ are the system current, the SVC current and the load current, respectively. Further on, the current of the SVC device $\left(i_{s v c}\right)$ can be written as: 


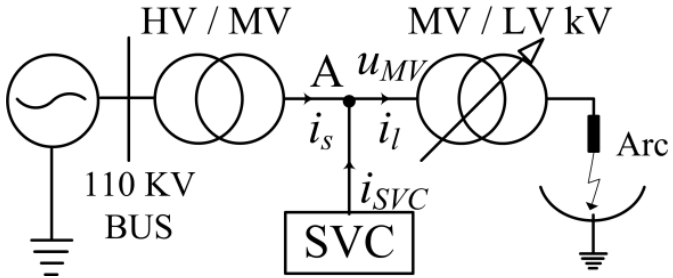

Fig. 4. Simplified scheme of the system.

$$
i_{S V C}=i_{T C R}+i_{F C}
$$

where $i_{T C R}$ and $i_{F C}$ are the TCR and FC currents, respectively. Based on equations (12) and (13), the reactive current components of the system current $\left(i_{q s}\right)$ and of the SVC device $\left(i_{q S V C}\right)$ in the d-q SRCS are obtained as:

$$
\begin{gathered}
i_{q S V C}=i_{q T C R}-i_{q F C}, \\
i_{q S}=i_{q l}+i_{q T C R}-i_{q F C} .
\end{gathered}
$$

In a fully compensated system, the reactive component of the system current $\left(i_{q s}\right)$ should be equal to zero. In other words, the reactive component of the TCR current should be adjusted so that $i_{q s}$ is equal to zero:

$$
\begin{aligned}
& i_{q l}+i_{q T C R}-i_{q F C}=0 \rightarrow \\
& \rightarrow i_{q l}=-\left(i_{q T C R}-i_{q F C}\right) .
\end{aligned}
$$

In this way, when the TCR controller regulates the system current $\left(i_{q s}\right)$ to zero, the reactive component of the load current $\left(i_{q l}\right)$ is fully compensated as follows from equation (16).

Fig. 5 shows the control scheme in the $d-q$ frame. Proportional-integral (PI) controllers are used in this control algorithm to set the reference for the $\mathrm{P}$ controller. Only one of the two PI controllers is used for setting the reference. The choice depends on the aim of the control algorithm (voltage, reactive power or flicker control). The power $q_{\text {ins }}$ and the voltage $U_{R M S}$ represent the instantaneous value of the reactive power and effective voltage at the MV level. The reference current $i_{q}^{\prime *}$ is compared to the $q$-component of the system current $i_{q s}^{\prime}$.

The control algorithm is based on the continuous monitoring and computing of the reactive current from the power system. A frequency range of 0.5 to $35 \mathrm{~Hz}$ should to be extracted from the whole spectrum of reactive current since this frequency spectrum (with observable magnitudes starting at less than $1.0 \%$ ) represents the main source of the flicker phenomena [13], [14]. Frequencies outside this range should not influence the operation of the controller because they can reduce its efficiency in terms of flicker reduction. This can be achieved by filtering the input signals of the P controller. In this study, filters based on the fast Fourier transform (FFT) were used.

Based on the actual values of the inputs, the control algorithm calculates the needed value of the susceptance $\left(B_{T C R}\right)$ in p.u. The correlation between the susceptance $B_{T C R}$ and the firing angle $\alpha$ is nonlinear and is described by the following equation [15]:

$$
B_{T C R}=\frac{2 \pi-2 \alpha+\sin 2 \alpha}{\pi X_{L}}
$$

where $X_{L}$ represents the maximum reactance of the TCR. By changing the susceptance of $B_{T C R}$, the effective value of the current through the reactor is changed and can be expressed as a function of the firing angle as follows:

$$
I_{L}=\frac{U_{r m s}}{\pi \omega L}(2 \pi-2 \alpha+\sin 2 \alpha)
$$

where $U_{r m s}$ is the effective value of the connected voltage, $L$ is the inductance of the TCR, and $\omega$ is the angular frequency of the voltage at the connection point [16].

The transfer function of the P controller from Fig. 5 can be expressed as follows:

$$
b^{\prime}=K_{p}\left(i_{q}^{\prime *}-i_{q s}^{\prime}\right)
$$

where $i_{q}^{\prime *}$ represents the reference value of the reactive current component at the MV level, while $i_{q s}^{\prime}$ is the measured value of the reactive component of the total system current $\left(i_{q s}\right)$. It should be mentioned that $i_{q s}^{\prime}=i_{q}^{\prime}$, as already shown.

Further on, the response time of a TCR $\left(T_{T C R}\right)$ is limited by the thyristor ignition delay [15]. Namely, the thyristor phase angle can be varied once in each half-cycle (in each phase). The ignition delay is not fixed and depends on the instant of the reference change (thyristor dead-time) and the delay between the sampling instant and the instant when the thyristor starts to conduct (firing delay). The required frequency for changing the value of parameter $b$ is six times the fundamental frequency for a three-phase 6-pulse TCR. In order to model the TCR delay, parameter $b$ should be multiplied by a first-order block with the time constant $T_{T C R}$ representing the average delay time as shown in equation (20).

$$
b=\frac{b^{\prime}}{1+s T_{T C R}} .
$$

Taking into account equation (19) the following is obtained:

$$
b=\frac{K_{p}\left(i_{q}^{\prime *}-i_{q}^{\prime}\right)}{\left(1+s T_{T C R}\right)}
$$




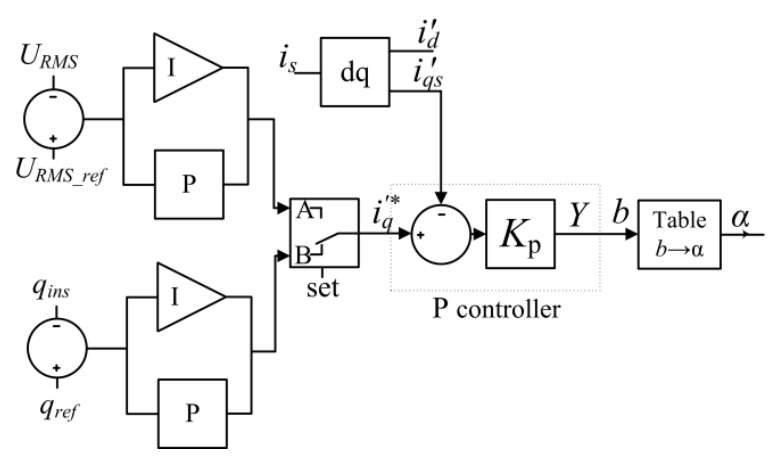

Fig. 5. Basic idea for the design of the control algorithm.

By using equation (21), a direct connection between the controller output and the mathematical model of the TCR is established. Based on this definition of parameter $b^{\prime}$, and by observing equations (10), (11) and (21), the following set of equations is obtained for the TCR current:

$$
\begin{aligned}
& i_{d}^{\prime}=\frac{1}{s+\frac{R^{\prime} \omega_{b}}{X^{\prime}}}\left[\frac{K_{p}\left(i_{q}^{\prime *}-i_{q}^{\prime}\right)}{1+s T_{T C R}} \frac{\omega_{b} u_{d}^{\prime}}{X^{\prime}}+\omega i_{q}^{\prime}\right] \\
& i_{q}^{\prime}=\frac{1}{s+\frac{R^{\prime} \omega_{b}}{X^{\prime}}}\left[\frac{K_{p}\left(i_{q}^{\prime *}-i_{q}^{\prime}\right)}{1+s T_{T C R}} \frac{\omega_{b} u_{q}^{\prime}}{X^{\prime}}-\omega i_{d}^{\prime}\right]
\end{aligned}
$$

where $u_{d}^{\prime}$, and $u_{q}^{\prime}$ are the $d$ - and $q$ - components of the measured voltage at the SVC connection point. This set of equations represents the mathematical model of a TCR controlled with a $\mathrm{P}$ controller. A block diagram of the mathematical model can be seen in Fig. 6 .

\section{Model Testing}

\section{A. Static Analysis}

In order to analyse the static accuracy, dynamic accuracy and stability of this model, its transfer function has to be determined. By inserting equation (22) into (23) the transfer function of the system shown in Fig. 6 is calculated as shown in equations (24) and (25).

For the determination of the static accuracy of the system, the static error in the stationary state of the system $(s=0)$ is observed. Theoretically, this error is minimal in the ideal case when the condition $i_{q}^{\prime}=i_{q}^{\prime *}$ is fulfilled. In this case, from equation (25), the gain $K_{p}$ of the $\mathrm{P}$ controller can be determined as follows:

$$
F(s)_{t r}=\frac{i_{q}^{\prime}}{i_{q}^{\prime *}}=\frac{K_{p} C A-K_{p} \omega_{b} B}{K_{p} C A-K_{p} B \omega_{b}+\omega_{b}^{2}} \neq 1, \forall K_{p} .
$$

Based on equation (26) it can be concluded that this controller with a negative feedback loop in the stationary state is not able to achieve its reference properly. In other words, for every value of the gain $K p$ there will be a static error. If the transfer function of the $\mathrm{P}$ controller is defined as:

$$
b^{\prime \prime}=K_{p}\left(-i_{q}^{\prime \prime *}-i_{q}^{\prime \prime}\right)
$$

then equations (22) and (23) become:

$$
\begin{aligned}
& i_{d}^{\prime \prime}=\frac{1}{s+\frac{R^{\prime} \omega_{b}}{X^{\prime}}}\left[\frac{K_{p}\left(-i_{q}^{\prime \prime *}-i_{q}^{\prime \prime}\right)}{1+s T_{S V C}} \frac{\omega_{b} u_{d}^{\prime}}{X^{\prime}}+\omega i_{q}^{\prime \prime}\right] \\
& i_{q}^{\prime \prime}=\frac{1}{s+\frac{R^{\prime} \omega_{b}}{X^{\prime}}}\left[\frac{K_{p}\left(-i_{q}^{\prime \prime *}-i_{q}^{\prime \prime}\right)}{1+s T_{S V C}} \frac{\omega_{b} u_{q}^{\prime}}{X^{\prime}}-\omega i_{d}^{\prime \prime}\right] .
\end{aligned}
$$

By inserting equation (28) into (29), the transfer function of the system is given in equation (30).

As previously discussed, for $s=0$ the following is obtained:

$$
\begin{gathered}
i_{q}^{\prime}=\frac{1}{s+\frac{R^{\prime} \omega_{b}}{X^{\prime}}}\left[\frac{K_{p}\left(i_{q}^{\prime *}-i_{q}^{\prime}\right)}{1+s T_{T C R}} \frac{\omega_{b} u_{q}^{\prime}}{X^{\prime}}-\omega \frac{1}{s+\frac{R^{\prime} \omega_{b}}{X^{\prime}}}\left[\frac{K_{p}\left(i_{q}^{\prime *}-i_{q}^{\prime}\right)}{1+s T_{T C R}} \frac{\omega_{b} u_{d}^{\prime}}{X^{\prime}}+\omega i_{q}^{\prime}\right]\right] \\
F(s)_{t r}=\frac{i_{q}^{\prime}}{i_{q}^{\prime *}}=\frac{K_{p} C s+K_{p} C A-K_{p} \omega_{b} B}{s^{3} T_{T C R}+s^{2}\left(1+2 A T_{T C R}\right)+s\left(2 A+A^{2} T_{T C R}-K_{p} C+\omega_{b}{ }^{2} T_{T C R}\right)+K_{p} C A-K_{p} B \omega_{b}+\omega_{b}^{2}},
\end{gathered}
$$

where:

$$
\begin{gathered}
A=\frac{R^{\prime} \omega_{b}}{X^{\prime}}, \quad B=\frac{\omega_{b} u_{d}^{\prime}}{X^{\prime}}, \quad C=\frac{\omega_{b} u_{q}^{\prime}}{X^{\prime}} . \\
F(s)_{t r}=\frac{K_{p} C s+K_{p} C A-K_{p} B \omega_{b}}{s^{3} T_{T C R}+s^{2}\left(1+2 A T_{T C R}\right)+s\left(A^{2} T_{T C R}-K_{p} C+\omega_{b}{ }^{2} T_{T C R}\right)+A^{2}-K_{p} C A+K_{p} B \omega_{b}+\omega_{b}^{2}}
\end{gathered}
$$




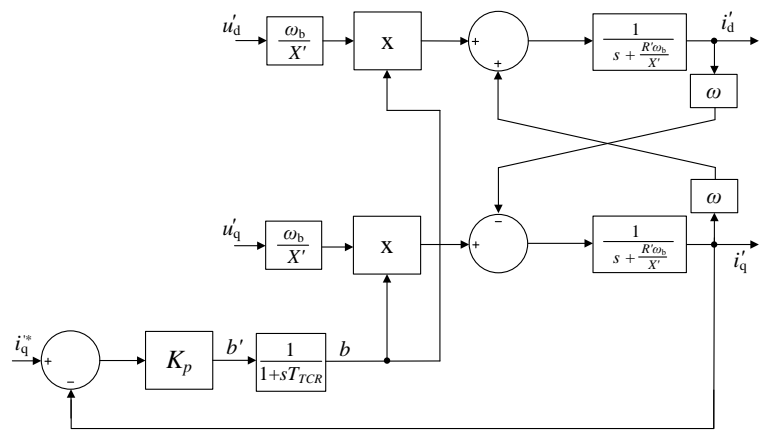

Fig. 6. The mathematical model of the TCR with a P controller.

$$
\begin{gathered}
F(s)_{t r}=\frac{i_{q}^{\prime}}{i_{q}^{\prime *}}=\frac{K_{p} C A-K_{p} \omega_{b} B}{A^{2}-K_{p} C A+K_{p} B \omega_{b}+\omega_{b}^{2}}=1 . \\
K_{p}=0.50
\end{gathered}
$$

Therefore, in the case of $K_{p}=0.50$ there is no static error. The value of $K_{p}$ has been determined from the transfer function when the ratio between $X_{1}$ and $R_{1}$ is constant and equal to $10 / 1$.

\section{B. Dynamic analysis}

For the dynamic analysis of the system, the output values under transient conditions have to be observed. It is very important that the mathematical model describes, in as much detail as possible, a real TCR. Therefore, the value of the TCR delay time $T_{T C R}$ is very important and has to be selected carefully.

In this paper, the value of $T_{T C R}$ has been determined based on a detailed simulation model of a TCR, which was modelled with the PSCAD simulation software. The step change of the reference current was initiated and the response of the TCR simulation model to this change was observed. Based on the simulation of different instants of reference change and on different SVC operating points an average response was estimated. Next, a step response of the mathematical model described by equation (30) for different values of $T_{T C R}$ was calculated.

Based on a mutual comparison of the average response obtained from the PSCAD simulation model and the results obtained from the mathematical model, the value of $T_{T C R}$ has been chosen. The selected value gives a response that best fits the response of the simulation model. In Fig. 7, line 1 represents the response of the TCR in the PSCAD simulation model, while lines 2, 3 and 4 represent the response of the mathematical model for different values of $T_{T C R}$.

The controller tracks its reference properly and reaches its value for all cases. In addition, the static error can be neglected. Based on this, it can be concluded that a $\mathrm{P}$ controller with a gain of $K_{p}=0.50$ and a value of $T_{T C R}=4 \mathrm{~ms}$ operates with a minimal static error and with a delay time. This correspondents to the average delay time of an actual TCR.

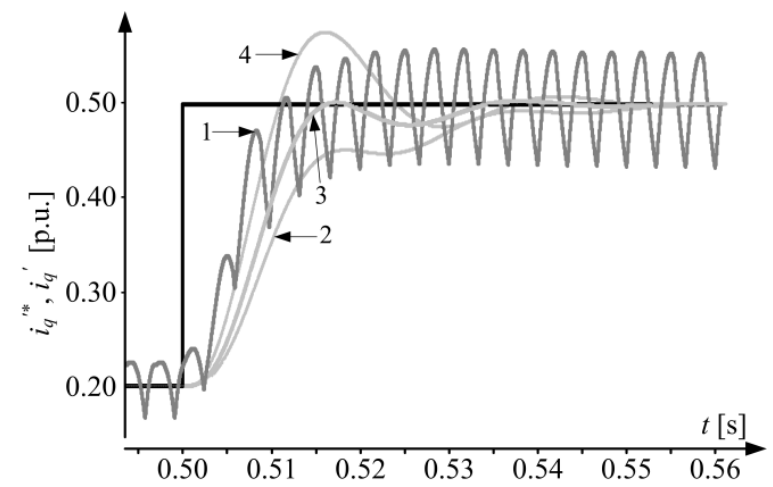

Fig. 7. The step response of the controller; 1 - response of the simulatedn TCR model; 2-response of the mathematical model, $T_{T C R}=6 \mathrm{~ms}$; 3-response of the mathematical model, $T_{T C R}=4 \mathrm{~ms}$; $4-$ response of the mathematical model, $T_{T C R}=2 \mathrm{~ms}$.

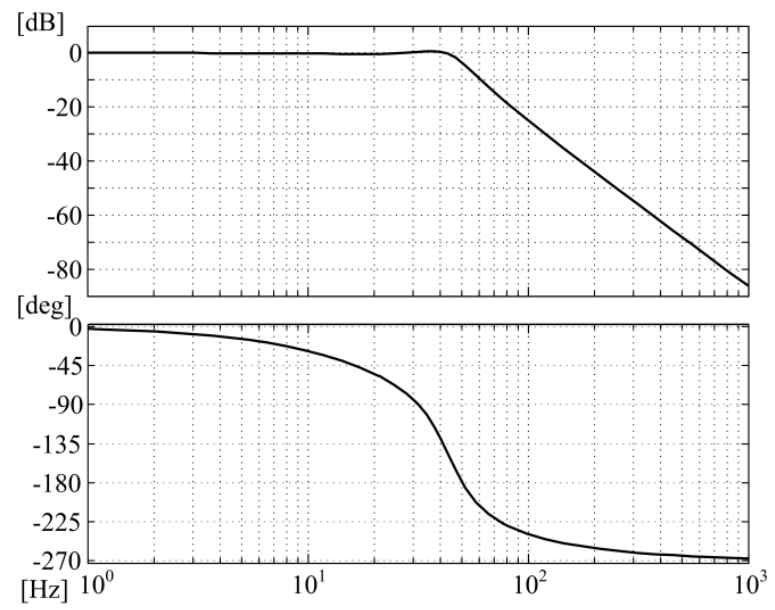

Fig. 8. Bode diagram of $F(s)_{t r}$ for values of $T_{T C R}=0.004 \mathrm{~s}$ and $K_{p}=0.50$.

The SVC current in the simulation model also contains harmonics.

The stability was evaluated by using the Bode stability criterion. According to this criterion, a closed-loop system will be stable if the value of the gain is less than 1 at the critical frequency. The critical frequency is equal to -180 degrees. The results obtained are shown in Fig. 8. Based on Fig. 8, it can be concluded that the system will be stable for the selected parameters $K_{p}$ and $T_{T C R}$.

\section{TEST System CONFIGURATION}

The SVC control system proposed in this paper has been applied to a realistic model of an actual steel factory. A simplified single-line diagram of the steel plant network under investigation is shown in Fig. 9.

The electric arc furnace was modelled as described in [2]. The furnace (the electric arc) is modelled as a voltage source. The amplitudes of the frequency components of that voltage source are time modulated to describe the arc-length variations that cause network-voltage fluctuations. To simulate the arc-length variation, the deterministic approach 


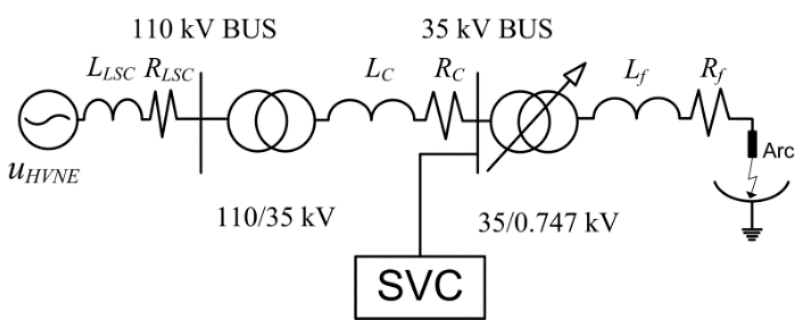

Fig. 9. Single-line scheme of the plant network.

TABLE I

VALUES OF THE PARAMETERS FOR THE MOdel SHOWN IN Fig. 9

\begin{tabular}{|ccc|}
\hline High-voltage & $S^{\prime}{ }_{s c}$ & $3200 \mathrm{MVA}$ \\
network equivalent & $u_{n}$ & $110 \mathrm{kV}$ \\
& $R / X$ & 0.1 \\
& $S_{t r 1}$ & $100 \mathrm{MVA}$ \\
$\operatorname{Tr} 110 / 35$ & $u_{n t r 1}$ & $110 / 35 \mathrm{kV}$ \\
& $u_{k t r 1}$ & $11 \%$ \\
& $R / X$ & 0.1 \\
& $S_{t r 2}$ & $80 \mathrm{MVA}$ \\
$\operatorname{Tr} 35 / 0.747$ & $u_{n t r 2}$ & $35 / 0.7473 \mathrm{kV}$ \\
& $u_{k t r 2}$ & $6.135 \%$ \\
cable resistance & $R / X$ & 0.1 \\
cable inductance & $R_{C}$ & $210 \cdot 10^{-3} \Omega$ \\
furnace cable resistance & $L_{C}$ & $2.8 \cdot 10^{-3} \mathrm{H}$ \\
furnace cable inductance & $R_{f}$ & $43 \cdot 10^{-3} \Omega$ \\
& $L_{f}$ & $1.11 \cdot 10^{-5} \mathrm{H}$ \\
\hline
\end{tabular}

TABLE II

PARAMETERS OF THE SVC

\begin{tabular}{|ccc|}
\hline reactor & $L_{S V C}$ & $0.102 \mathrm{H}$ \\
resistor & $R_{S V C}$ & $3.204 \Omega$ \\
filter 2. harmonic & $F C_{2 H}$ & $35 \mathrm{MVAR}$ \\
filter 3. harmonic & $F C_{3 H}$ & $35 \mathrm{MVAR}$ \\
filter 4. harmonic & $F C_{4 H}$ & $35 \mathrm{MVAR}$ \\
\hline
\end{tabular}

was used, where the arc length varies according to a sine function with a selected frequency. For the arc-length variation, three frequencies were used, namely 5, 9 and $13 \mathrm{~Hz}$. In each simulated case, the parameters of the electric arc furnace model were adjusted so that the model generated the same level of flicker $\left(P_{s t}\right)$ at the $110 \mathrm{kV}$ voltage level. The model was calibrated according to field measurements.

The network model involves a high-voltage network equivalent with its short-circuit inductance $\left(L_{L S C}\right)$ and resistance $\left(R_{L S C}\right)$, a $110 / 35 \mathrm{kV}$ transformer, the resistance $\left(R_{C}\right)$ and inductance $\left(L_{C}\right)$ of the cable between the substation and the furnace transformer, the $35 / 0.74 \mathrm{kV}$ furnace transformer, and the inductance $\left(L_{f}\right)$ and resistance $\left(R_{f}\right)$ of the cable between the furnace transformer and the furnace electrodes. The values of these parameters are shown in Table I and they correspond to the actual parameters of the steel plant. The short-circuit power $\left(S{ }^{\prime}{ }_{s c}\right)$ at the $110 \mathrm{kV}$ bus is equal to 3200 MVA. The SVC device is connected to the $35 \mathrm{kV}$ voltage level. The parameters of the SVC are summarised in Table II.

\section{SIMULATION RESULTS}

\section{A. Simulations without the SVC}

A simulation of a steel factory model without the SVC was carried out first. A total simulation time ( $T$ ) of 20 seconds was chosen with a sampling time of $15 \mu$ s. Waveforms of the active power $(P)$ and reactive power $(Q)$ are shown in Fig. 10 (the frequency of the arc-length modulation is equal to $9 \mathrm{~Hz}$ ). $P_{\text {furnace }}$ and $Q_{\text {furnace }}$ represent the active and reactive power of the arc furnace, respectively, while $P_{\text {net } 35 \mathrm{kV}}$ and $Q_{\text {net } 35 \mathrm{kV}}$ represent the active and reactive power from the power system at the $35-\mathrm{kV}$ level. The negative impacts of the electric arc furnace on the power system (fluctuations of the active and reactive power) can be clearly seen in the figure. The oscillations of the active and reactive power from the power system are at unacceptably high levels.

Fig. 11 shows the rms voltage fluctuations in p.u. at $35 \mathrm{kV}$ level without the SVC. The oscillations of the rms voltage that cause flicker in the network can be seen.

The numerical values of $P, Q$ and $P_{s t}$ obtained by these simulations (with different frequencies of the arc length modulation) are listed in Table III. The values of $\cos \varphi$ in the table (table row 'Network') are related to the power factor at the $110 \mathrm{kV}$ busbars.

\section{B. Simulations with the SVC}

Simulations of the steel factory model with the SVC connected to the $35 \mathrm{kV}$ voltage level have also been carried out. The parameters of the P and PI controllers used in the simulations are given in Table IV. The parameters of the PI controller were chosen so that approximately a first order response of the control system was achieved.

Firstly, simulations of the SVC operating in flicker compensation mode with different frequencies of arc-length modulation were carried out. Table 5 lists the numerical values of $P, Q$ and $P_{s t}$ obtained by simulations of a full load with the connected SVC (for different frequencies of arc length). A load change was also simulated.

The waveforms of the simulated signals (frequency of arc-length modulation $9 \mathrm{~Hz}$ ) active and reactive power at the $35 \mathrm{kV}$ level, can be seen in Fig. 12, while Fig. 13 shows the rms voltage fluctuation (in p.u.) at the $35 \mathrm{kV}$ level. For the time period $t<6 \mathrm{~s}$ the furnace is operated at full power. Based on Fig. 12 and the data in Table V, it can be concluded that the negative effects of the electric arc furnace can be reduced to an acceptable level by the SVC. By comparing Fig. 10 and Fig. 12 (for $\mathrm{t}<6 \mathrm{~s}$ ), it can be seen that both the oscillations and the reactive power that the electric arc furnace withdraws from the network are reduced. As a result of the reduced 
TABLE III

Simulated Values of Active $(P)$ And Reactive $(Q)$ Power AND FLICKER LEVEL $\left(P_{S T}\right)$ WiTHOUT THE CONNECTED SVC AT THE 35-KV LEVEL, For DifFERENT ARC-Length Modulations

\begin{tabular}{|cccccc|}
\hline $\begin{array}{c}\text { Arc length } \\
\text { modulation }\end{array}$ & $U_{35}=1$ & $P$ & $Q$ & & \\
& p.u. & {$[\mathrm{MW}]$} & [MVAR] & $\cos \varphi$ & $P_{\text {st }}$ \\
& Network & 57.84 & 69.66 & 0.593 & \\
& Furnace & 56.13 & 56.04 & 0.706 & 1.55 \\
& Network & 57.74 & 70.26 & 0.589 & \\
$9 \mathrm{~Hz}$ & Furnace & 56.04 & 56.7 & 0.704 & \\
& Network & 57.83 & 69.96 & 0.591 & \\
$11 \mathrm{~Hz}$ & Furnace & 56.11 & 56.32 & 0.705 & 1.55 \\
& Network & 57.74 & 69.97 & 0.591 & \\
$13 \mathrm{~Hz}$ & Furnace & 56.03 & 56.30 & 0.704 & \\
& & & & & \\
\hline
\end{tabular}

TABLE IV

PARAMETERS OF CONTROLLERS

\begin{tabular}{|ccc|}
\hline Controller & Parameter & Value \\
$\mathrm{P}$ & $K_{p}$ & 0.5 \\
& $K_{p u}$ & 10 \\
PI (voltage control) & $T_{i u}$ & $2.5 \mathrm{~ms}$ \\
PI (reactive power control) & $K_{p q}$ & 0.001 \\
& $T_{i q}$ & $100 \mathrm{~ms}$ \\
\hline
\end{tabular}
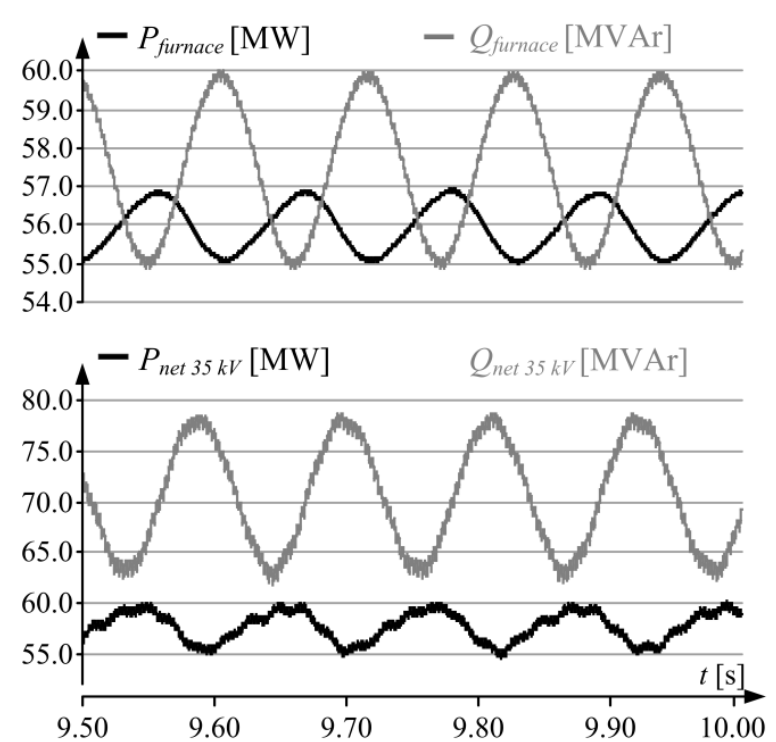

Fig. 10. Simulated active and reactive power without SVC at 35-kV level (frequency of arc length modulation $9 \mathrm{~Hz}$ ).

reactive power fluctuations, the level of flicker is also reduced. The voltage waveforms at the $35 \mathrm{kV}$ level with the connected SVC are shown in Fig. 13. At instant $t=6 \mathrm{~s}$, the furnace load is changed. However, it does not have an impact on the proper operation of the controller. The controller continues to minimize the negative effects of the furnace (Fig. 12) at the reduced load.

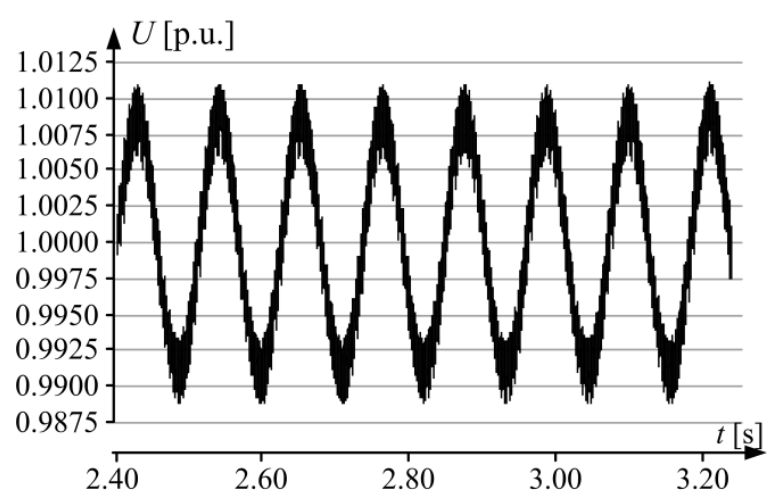

Fig. 11. Fluctuations of rms voltage at $35 \mathrm{kV}$ level (frequency of arc length modulation $9 \mathrm{~Hz}$ ).

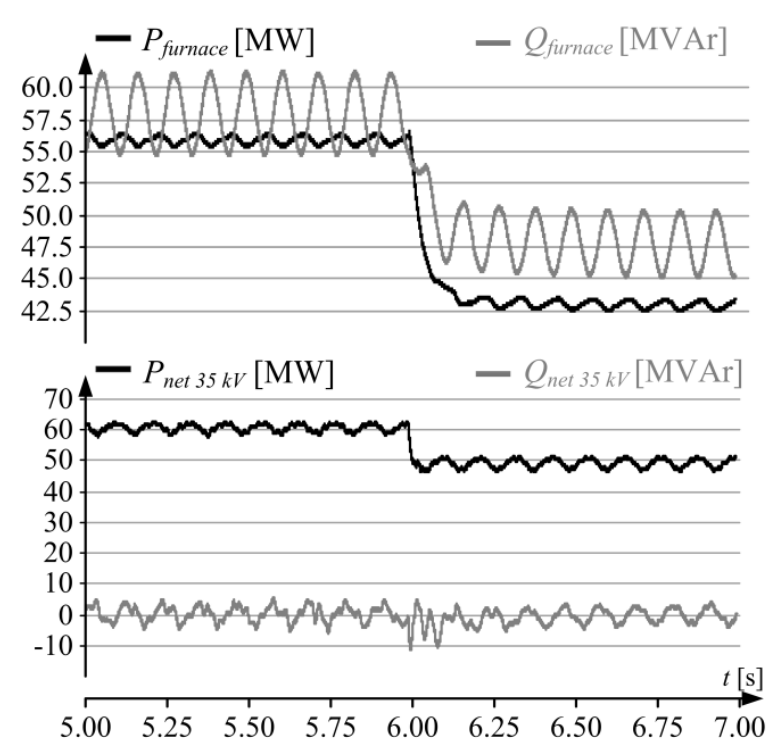

Fig. 12. Simulated active and reactive power with the connected SVC at the35 $\mathrm{kV}$ level (frequency of arc-length modulation 9 $\mathrm{Hz}$ ).

The waveforms of the thyristors ignition angle can be seen in Fig. 14.

Lastly, the SVC operating in voltage regulation mode has been simulated. For the time period $t<6 \mathrm{~s}$, the furnace operates with a full nominal load. Fig. 15 shows the rms voltage fluctuation in this case. At instant $t=6 \mathrm{~s}$, the furnace load is changed. As a result, the voltage at the PCC is increased. It can be seen from Fig. 15 that the system reaches the desired value of the voltage after a short transient period. The transitional process is quick and without over-current.

By comparing Fig. 15 and Fig. 13, it can be seen that the fluctuations of the rms voltage value in both figures are almost the same. In other words, the flicker levels are almost the same. Based on the simulation results, it can be concluded that the SVC has also the ability to reduce flicker in the voltage control mode. 
TABLE V

Simulated Values With the ConNected SVC for the Period $T<6$ S AT THE $35 \mathrm{KV}$ LEVEL

\begin{tabular}{|c|c|c|c|c|c|}
\hline $\begin{array}{l}\text { Arc length } \\
\text { modulation }\end{array}$ & & $\begin{array}{c}P \\
{[\mathrm{MW}]}\end{array}$ & $\begin{array}{c}Q \\
{[\mathrm{MVAR}]}\end{array}$ & $\cos \varphi$ & $P_{s t}$ \\
\hline \multirow{2}{*}{$5 \mathrm{~Hz}$} & Network & 60.62 & $\approx 0$ & 0.996 & \multirow{2}{*}{0.56} \\
\hline & Furnace & 56.24 & 56.83 & 0.701 & \\
\hline \multirow{2}{*}{$9 \mathrm{~Hz}$} & Network & 60.47 & $\approx 0$ & 0.996 & \multirow{2}{*}{0.65} \\
\hline & Furnace & 56.24 & 57.54 & 0.699 & \\
\hline \multirow{2}{*}{$11 \mathrm{~Hz}$} & Network & 60.57 & 3.13 & 0.992 & \multirow{2}{*}{0.76} \\
\hline & Furnace & 56.05 & 57.33 & 0.699 & \\
\hline \multirow{2}{*}{$13 \mathrm{~Hz}$} & Network & 61.25 & 6.93 & 0.981 & \multirow{2}{*}{0.96} \\
\hline & Furnace & 56.08 & 56.90 & 0.701 & \\
\hline
\end{tabular}

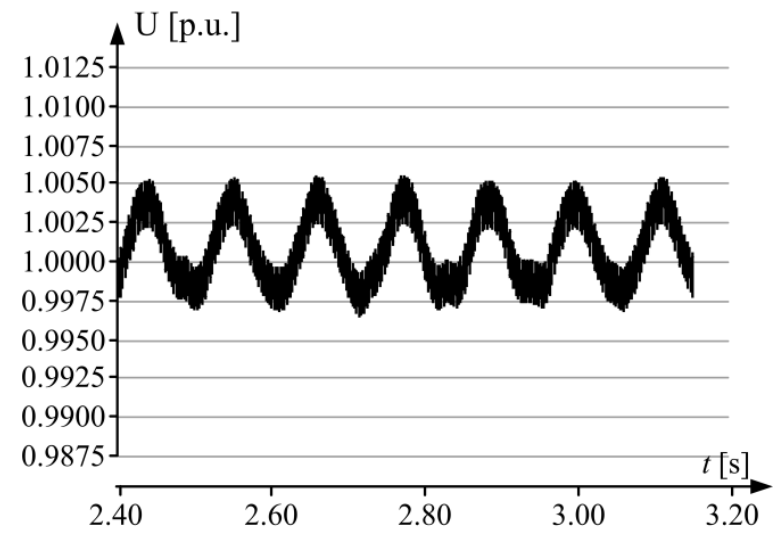

Fig. 13. Fluctuations of the rms voltage at the $35 \mathrm{kV}$ level with the connected SVC (frequency of arc-length modulation $9 \mathrm{~Hz}$ ).

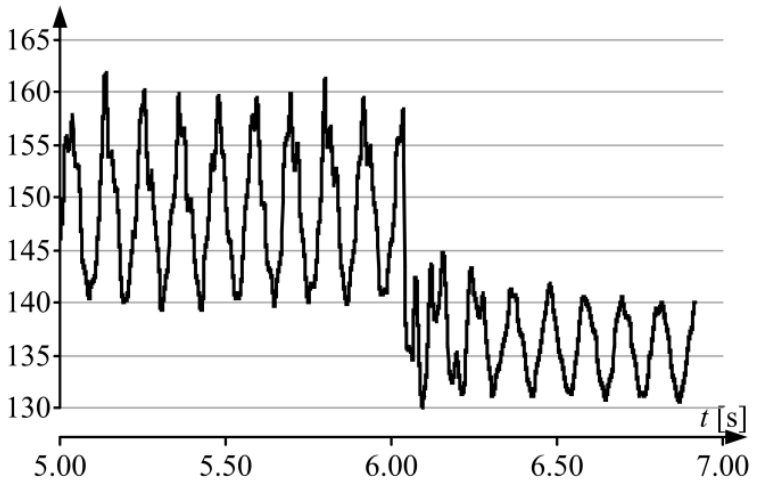

Fig. 14. Values of tyristors ignition angle, $\alpha$ (frequency of arc-length modulation $9 \mathrm{~Hz}$ ).

\section{ASSESSMENT OF THE CONTROLLER CHARACTERISTIC}

From the data in Table V, it can be concluded that the proposed controller has the ability to fully compensate the reactive power and power factor $(\cos \varphi)$ along with the ability to reduce the level of flicker to an acceptable level for each arc-length modulation frequency. In Fig. 16 the flicker levels

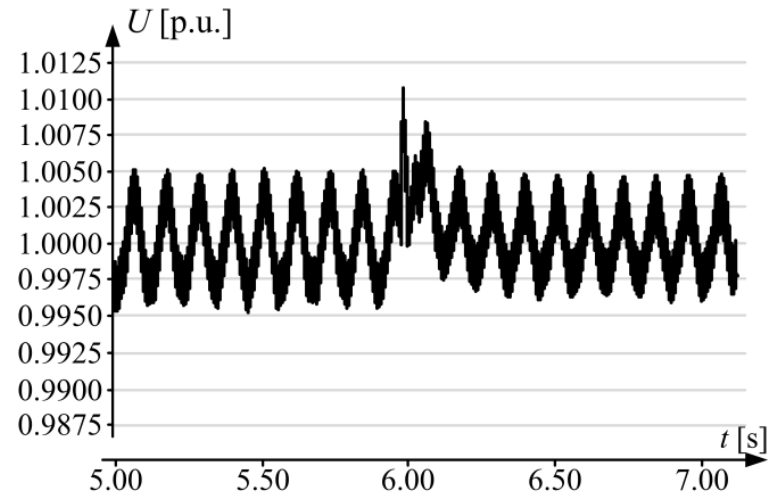

Fig. 15. Fluctuations of the rms voltage at the $35 \mathrm{kV}$ level with the connected SVC, voltage control.

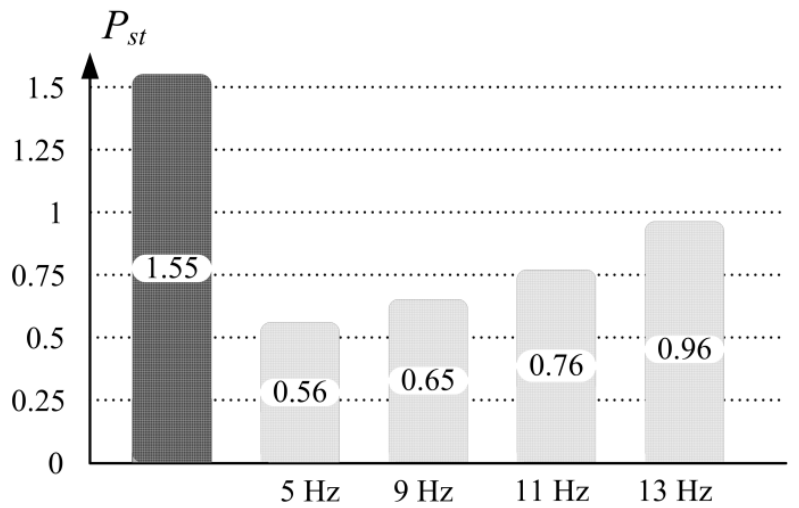

Fig. 16. Simulated values of flicker level without and with the connected SVC for different modulation frequencies (for $P_{\text {furnace }} \approx 56.2 \mathrm{MW}$ ).

for different modulations of arc length are shown. Based on this, it can be concluded that with an increasing modulation frequency, the ability of the controller to reduce flicker level is reduced. In other words, the controller has more difficulty following the fluctuations at higher frequencies. It is widely accepted that an SVC can reduced flicker by up to a factor of 2 .

On the basis of the data shown in Fig. 16, it can be concluded that the frequency of $11 \mathrm{~Hz}$ for arc-length modulation is better suited for use in the simulation studies than the usually used frequency of $9 \mathrm{~Hz}$. Although the human eye is more sensitive to $9 \mathrm{~Hz}$, the frequency of $11 \mathrm{~Hz}$ gives more realistic results in terms of the SVC dynamic capabilities.

In addition to flicker compensation and full compensation of the reactive power, there are some additional advantages of the proposed controller such as the need for only one network measurement point and the ability to regulate voltage at the connection point.

\section{CONCLUSIONS}

In this paper, the development and implementation of an SVC controller in the feedback-loop control strategy has been presented. Based on the transfer function of the TCR mathematical model, a controller has been designed in the $\mathrm{d}-\mathrm{q}$ 
coordinate system. In addition, a stability analysis of the system has been carried out. Using an actual industrial network model, the proposed controller was validated by means of simulations. The simulation results showed that the proposed model can be successfully used to compensate reactive power, to reduce flicker level or to regulate voltage. The main advantages of the proposed controller are its good flicker compensation, the ability to regulate voltage at the PCC and that its implementation requires only one point for network measurement. One measurement point means a lower price of the system installation and a reduced possibility of failure. The control algorithm was developed for the positive-system currents. Arc-furnace unbalance will be investigated in a future study.

The control algorithm proposed in this paper can be also applied to other types of FACTS devices such as a STATCOM or a thyristor controlled series compensator. Future work on the subject will include the evaluation of the proposed controller in a real-time digital simulator (controller in the loop).

\section{ACKNOWLEDGMENT}

Operation part financed by the European Union, European Social Fund. Operation implemented in the framework of the Operational Programme for Human Resources Development for the Period 2007-2013, Priority axis 1: Promoting entrepreneurship and adaptability, Main type of activity 1.1.: Experts and researchers for competitive enterprises.

\section{REFERENCES}

[1] H. Samet and M. E. Hamedani Golshan, “A wide nonlinear analysis of reactive power time series related to electric arc furnaces,” Electrical Power and Energy Systems, Vol. 36, No. 1, pp. 127-134, Mar. 2012.

[2] G. C. Montanari, M. Loggini, A. Cavallini, L. Pitti, and D. Zaninelli, "Arc-furnace model for the study of flicker compensation in electrical networks," IEEE Trans. Power Del., Vol. 9, No. 4, pp. 2026-2036, Oct. 1994.

[3] J. Wang, C. Fu, and Y. Zhang, "SVC Control System Based on Instantaneous Reactive Power Theory and Fuzzy PID," IEEE Trans. Ind. Electron., Vol. 55, No. 4, pp. 1658-1665, Apr. 2008.

[4] Q. Zhao and J. Jiang, "Robust SVC controller design for improving power system damping," IEEE Trans. Power Syst., Vol. 10. No. 4, pp. 1927-1932, Nov. 1995.

[5] M. C. Lima and H. Tyll, "An overview of static VAR compensators technology evolution on a Brazilian generation and transmission utility," Proc. IEEE 10th Int. Conf. Harmonics Quality Power, Vol. 2, pp. 601-606, 2002.

[6] A. F. Zobaa, and M. A. Jovanović, "A comprehensive overview on reactive power compensation technologies for wind power applications," Proc. IEEE 12th Int. Power Electron. Motion Control Conf., pp. 1848-1852, 2006.

[7] H. Samet and M. Parniani, "Predictive method for improving SVC speed in electric arc furnace compensation," IEEE Trans. Power Del., Vol. 22, No. 1, pp. 732-734, Jan. 2007.
[8] H. Samet and M. E. H. Golshan, "Employing stochastic models for prediction of arc furnace reactive power to improve compensator performance," IET Generation, Transmission and Distribution, Vol. 2, No. 4, pp. 505-515, Jul. 2008.

[9] C. Cheng and Y. Y. Hsu, "Damping of generator oscillations using an adaptive static VAR compensator," IEEE Trans. Power Syst., Vol. 7, No. 2, pp. 718-725, May 1992.

[10] X. Du, L. Peng, and L. Zhou, “A hybrid reactive power compensation system consisting of multi capacitor banks and a SVG,” Power System Technology, Vol. 32, No. 14, pp. 39-43, May 2008.

[11] E. H. Mamdani, "Application of fuzzy algorithm for control of simple dynamic plant,” in Proc. the IEEE, Vol. 121, No. 12, pp. 1585-1588, Dec. 1974.

[12] T. Abdelazim and O. P. Malik, "Intelligent SVC control for transient stability enhancement," IEEE Power Engineering Society General Meeting, Vol. 2, pp. 1701-1707, Jun. 2005.

[13] C.J. Wu and T.H. Fu, "Effective voltage flicker calculation algorithm using indirect demodulation method," Power, Energy, \& Industry Applications, Vol. 150, No. 4, pp. 493-500, Jul. 2003.

[14] J. W. Smith, "Voltage Flicker Primer," Submitted to the IEEE SCC 21 P1547 Working Group, 17, Jun. 1999.

[15] R. M. Mathur and R. K. Varma, Thyristor-based FACTS Controllers for Electrical Transmission Systems, IEEE Press, pp. 45-50, 2002.

[16] A. García-Cerrada, P. García-González, R. Collantes, T. Gómez, and J. Anzola, "Comparison of thyristorcontrolled reactors and voltage-source inverters for compensation of flicker caused by arc furnaces," IEEE Trans. Power Del., Vol. 15, No. 4, pp. 1225-1231, Oct. 2000.

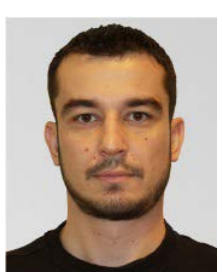

Ljubiša Spasojević received his B.S. degree in Electrical Engineering from the University of Novi Sad, Novi Sad, Serbia, in 2008. He is presently working as a Researcher in the Faculty of Electrical Engineering, University of Ljubljana, Ljubljana, Slovenia. His current research interests include power quality in large industrial networks.

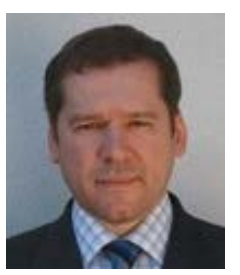

Igor Papič received his B.S., M.S. and Ph.D. degrees, all in Electrical Engineering, from the University of Ljubljana, Ljubljana, Slovenia, in 1992, 1995 and 1998, respectively. From 1994 to 1996 he was employed by the Siemens Power Transmission and Distribution Group in Erlangen, Germany. He is presently working as a Professor in the Faculty of Electrical Engineering, University of Ljubljana. In 2001, he was a Visiting Professor at the University of Manitoba, Winnipeg, Canada. His current research interests include power conditioners, FACTS devices, power quality and active distribution networks.

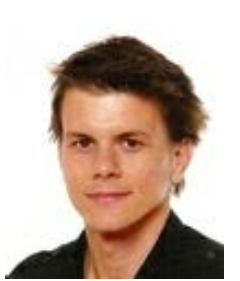

Boštjan Blažič received his B.S., M.S. and Ph.D. degrees, all in Electrical Engineering, from the University of Ljubljana, Ljubljana, Slovenia, in 2000, 2003 and 2005, respectively. $\mathrm{He}$ is presently working as an Assistant in the Faculty of Electrical Engineering, University of Ljubljana. His current research interests include power quality, distributed generation, mathematical analysis and the control of power converters. 